\title{
Produção de lenha e forragem de Poincianella pyramidalis (Tul.) L. P. Queiroz submetida à poda anual ${ }^{\mathrm{I}}$
}

\author{
Firewood and forage production from Poincianella pyramidalis (Tul.) L. P. Queiroz \\ subjected to anual pruning
}

\section{William de Sousa Santos ${ }^{\mathrm{I}}$, Olaf Andreas BakkeII, Wellington de Sousa Santos ${ }^{\mathrm{III}}$, Amanda de Araújo Silva ${ }^{\mathrm{IV}}$, Sérvio Túlio Pereira Justinov ${ }^{\mathrm{v}}$}

\begin{abstract}
Resumo
Algumas espécies lenhosas da caatinga possuem potencial para produzir forragem de qualidade a baixo custo. Suas folhas e ramas finas podem ser consumidas no campo ou fornecidas como feno, se forem coletadas na estação chuvosa, período de abundância, para suplementar a dieta dos animais no período seco do ano. Poincianella pyramidalis (Tul.) L. P. Queiroz (catingueira) aparece com bom potencial para a produção de forragem. O objetivo deste trabalho foi avaliar a produção de forragem de catingueira em função da intensidade de poda de suas ramas em dois anos consecutivos, e o efeito desta no DAP e acúmulo de biomassa lenhosa, e na forragem herbácea produzida sob e fora da projeção da copa. O trabalho foi desenvolvido na Fazenda Lameirão, Santa Terezinha-PB, Brasil. As ramas foram coletadas de 20 catingueiras adultas, de acordo com 5 intensidades de poda: $\mathrm{T} 1=0 \%, \mathrm{~T} 2=25 \%, \mathrm{~T} 3=50 \%, \mathrm{~T} 4=75 \%$ e $\mathrm{T} 5$ $=100 \%$ de poda. A produção média de forragem variou entre os tratamentos de 2,19 a 7,07 kg. árvore ${ }^{-1}(\mathrm{MS})$ em 2016 e de 1,33 a 2,41 kg. árvore-1 (MS) em 2017. A produção de forragem herbácea foi maior sob (1,60 t. $\mathrm{ha}^{-1}$ ) (MS) do que fora (1,07 t. ha-1) (MS) da copa. O corte das ramas não afeta o acúmulo de biomassa lenhosa e nem a produção herbácea. A composição química das forragens é satisfatória à alimentação animal.
\end{abstract}

Palavras-chave: Biomassa vegetal; Catingueira; Florestas secas; Manejo florestal

\begin{abstract}
Some woody species of the caatinga have the potential to produce high quality forage at a low cost. Its leaves and thin branches can be foraged in the field or supplied as hay if they are collected in the rainy season, period of food abundance, to supplement the diet of the animals in the dry period of the year. Poincianella pyramidalis (Tul.) L. P. has a high potential for forage production. The objective of this study was to evaluate forage production of $P$. pyramidalis according to the pruning intensity of its fine branches in two consecutive years, the effect of prunning on DAP and accumulation of woody biomass, and on the herbaceous forage produced under and outside the canopy projection. The study was carried out at Fazenda Lameirão, Santa Terezinha - Paraíba state, Brazil. Fine branches were collectect from 20 adult $P$. pyramidalis according to five pruning intensities: $\mathrm{T} 1=0 \%, \mathrm{~T} 2=25 \%, \mathrm{~T} 3=50 \%, \mathrm{~T} 4=75 \%$ and $\mathrm{T} 5=100 \%$ of the fine branches. The average forage production ranged from 2.19 to $7.07 \mathrm{~kg}^{-\mathrm{tree}^{-1}}$ (DM) in 2016, and from

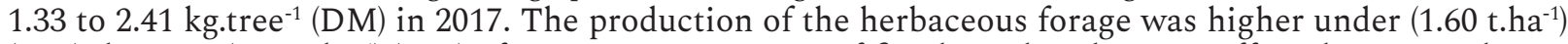
(DM) than out (1.07 t.ha' ${ }^{-1}$ (DM) of tree canopy. Pruning of fine branches does not affect the accumulation of woody biomass nor the herbaceous biomass production. Forage from P. pyramidalis fine branches and herbs showed to be suitable to animal feeding.

Keywords: Plant biomass; Catingueira; Dry forests; Forest management

\footnotetext{
Parte da dissertação de mestrado do primeiro autor no Programa de Pós-graduação em Ciências Florestais da Universidade Federal de Campina Grande (UFCG), Patos (PB), Brasil.

Engenheiro Florestal, MSc., Programa de Pós-graduação em Ciência Animal, Universidade Federal de Campina Grande/Centro de Saúde e Tecnologia Rural, Caixa Postal 61, CEP 58708-110, Patos (PB), Brasil. william.ufcg@gmail.com (ORCID: 0000-0001-7659-1618)

Engenheiro Agrônomo, PhD., Professor do Programa de Pós-graduação em Ciências Florestais, Centro de Saúde e Tecnologia Rural, Universidade Federal de Campina Grande, Caixa Postal 61, CEP 58708-110, Patos (PB), Brasil. obakke@cstr.ufcg.edu.br (ORCID:0000-0003-2324-0165) Caixa Postal 61, CEP 58708-110, Patos (PB), Brasil. welliington.ifpb@gmail.com (ORCID: 0000-0001-9873-7083)

Médica Veterinária, Mestranda do Programa de Pós-graduação em Ciência Animal, Centro de Saúde e Tecnologia Rural, Universidade Federal de Campina Grande, Caixa Postal 61, CEP 58708-110, Patos (PB), Brasil. amandavetufcg@gmail.com (ORCID: 0000-0002-1908-0720)

Engenheiro Florestal, Mestrando do Programa de Pós-graduação em Ciências Florestais, Centro de Saúde e Tecnologia Rural, Universidade Federal de Campina Grande, Caixa Postal 61, CEP 58708-110, Patos (PB), Brasil. serviojustino@outlook.com (ORCID: 0000-0003-1029-7808)
}

III Engenheiro Florestal, Unidade Acadêmica de Engenharia Florestal, Centro de Saúde e Tecnologia Rural, Universidade Federal de Campina Grande,
\end{abstract}




\section{Introdução}

Entre as regiões de clima semiárido no mundo, o Nordeste brasileiro destaca-se por ser uma das mais populosas com cerca de 22,5 milhões de habitantes (MEDEIROS et al., 2012). A região apresenta grande dependência econômica dos recursos florestais da caatinga, tais como a lenha, estacas e mourões (FRANCELINO et al., 2003; SILVA et al., 2009; MACHADO; GOMES; MELLO, 2010), além de produtos não madeireiros como folhas, flores e frutos, que constituem uma das principais fontes de alimento para os animais (COSTA et al., 2011; SILVA et al., 2012; ARAÚJO FILHO, 2013).

A vegetação do bioma Caatinga é caracterizada pelo comportamento xerófilo e caducifólio da maior parte de suas espécies lenhosas na estação seca e pela presença de um estrato herbáceo abundante na estação chuvosa, além de cactáceas e bromeliáceas (DRUMOND et al., 2000). Outra característica dessa vegetação é o endemismo de muitas de suas espécies (PRADO, 2003).

A estação chuvosa no Sertão paraibano, onde se encontra a área de estudo, ocorre entre os meses de janeiro a abril. Nesse quadrimestre, os índices pluviométricos variam de 500 a 700 $\mathrm{mm}$, apresentando alta variabilidade espacial e temporal (AGÊNCIA EXECUTIVA DE GESTÃO DAS ÁGUAS, 2009), o que influencia diretamente nas formações vegetacionais e em todo o ordenamento da produção agrícola e pecuária da região. É nessa estação que há uma abundância de forragem de boa qualidade, proporcionada, principalmente, pelas espécies herbáceas sazonais. $\mathrm{Na}$ estação seca, a produção de biomassa herbácea cessa e a remanescente ainda não consumida é de baixa qualidade. Nesse período, a forragem de origem arbustivo-arbórea é de importância crucial para a alimentação dos rebanhos, pois as folhas amadurecem, caem e ficam disponíveis aos animais. Uma alternativa a essa situação seria a coleta e o armazenamento da forragem arbustivo-arbórea na estação úmida que, posteriormente, poderia ser fornecida na estação seca sob a forma de feno ou silagem no cocho.

Algumas espécies lenhosas da caatinga possuem potencial para produzir forragem de qualidade a baixo custo. Suas folhas e ramas finas podem ser consumidas no campo ou fornecidas como feno, se forem coletadas na estação chuvosa, período de abundância, para suplementar a dieta dos animais no período seco do ano. Entre as espécies com potencial forrageiro da caatinga, a catingueira pode contribuir por meio da deposição de suas folhas secas, com até $35 \%$ da forragem consumida por caprinos, ovinos e bovinos durante a estação seca (ARAÚJO FILHO, 2013). Esse autor ressalta que a referida espécie pode ser podada, na época das chuvas, para produção de feno a fim de ser fornecida aos animais na estação seca. Na Paraíba, especialmente na microrregião do Cariri, a espécie constitui uma importante fonte de forragem para os caprinos na estação seca, participando com até $12,5 \%$ da sua alimentação (LEITE; VIANA, 1986; LIMA JÚNIOR, 2006).

Além de apresentar-se como excelente forrageira, a madeira de catingueira é bastante utilizada nas propriedades rurais na manutenção e construção de currais (estacas e mourões) e como fonte energética na indústria ceramista na região semiárida (ALMEIDA; AQUINO; AGUIAR, 2003; MACHADO; GOMES; MELLO, 2010).

A catingueira é uma Fabaceae arbórea endêmica da Caatinga que possui ampla disseminação nesse bioma. A espécie é encontrada em diversas associações vegetais nos Estados do Piauí, Ceará, Rio Grande do Norte, Paraíba, Pernambuco, Alagoas, Sergipe e Bahia (SILVA et al., 2009).

Este estudo avaliou a produção de forragem de catingueira em função da intensidade da poda anual das suas ramas periféricas em dois anos consecutivos, o efeito dessa poda no incremento do Diâmetro à Altura do Peito (DAP) e no acúmulo estimado de biomassa lenhosa, bem como a forragem herbácea produzida sob e fora da projeção da copa das árvores podadas. 


\section{Material e métodos}

\section{Caracterização da área de estudo}

O estudo foi realizado na Fazenda Lameirão, pertencente à Universidade Federal de Campina Grande. A propriedade localiza-se na região Nordeste do Brasil, mesorregião do Sertão da Paraíba, município de Santa Terezinha, com área total de 97,6 ha sob as coordenadas $7^{\circ} 02^{\prime}$ $56.8^{\prime \prime}$ Sul e $37^{\circ} 29^{\prime} 36.2^{\prime \prime}$ Oeste (Figura 1).

Figura 1 - Localização da Fazenda Lameirão, Município de Santa Terezinha-PB, Brasil. Adaptado de IBGE (2010)

Figure 1 - Location of Fazenda Lameirão, Municipality of Santa Terezinha-PB state, Brazil. Adapted from IBGE (2010)
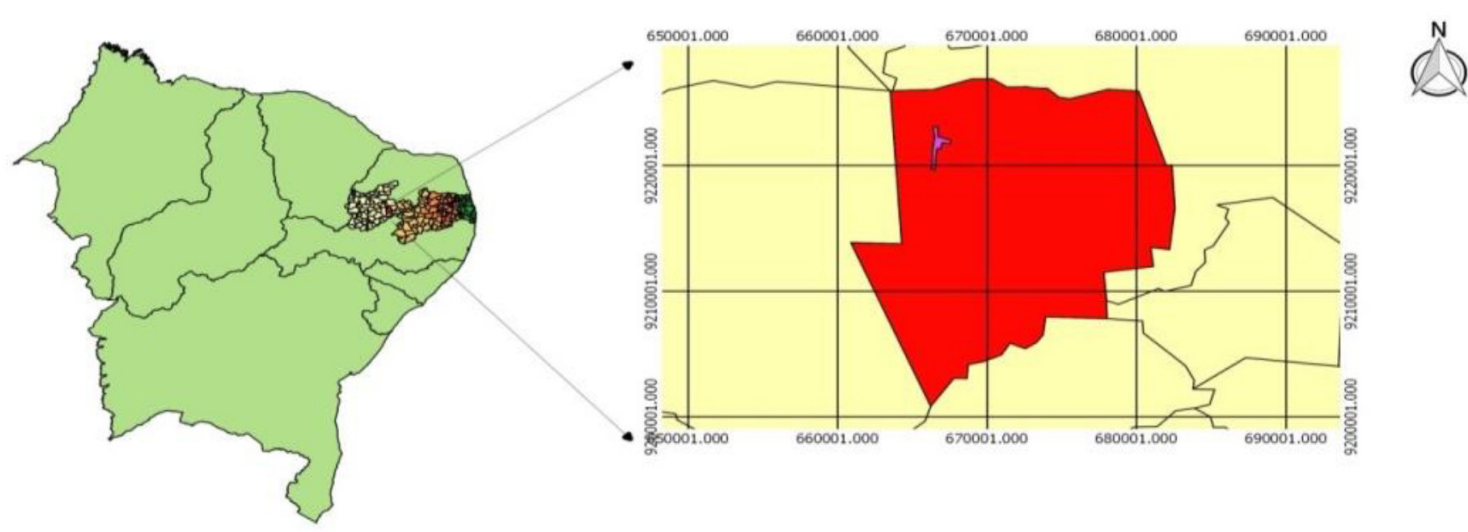

Legenda
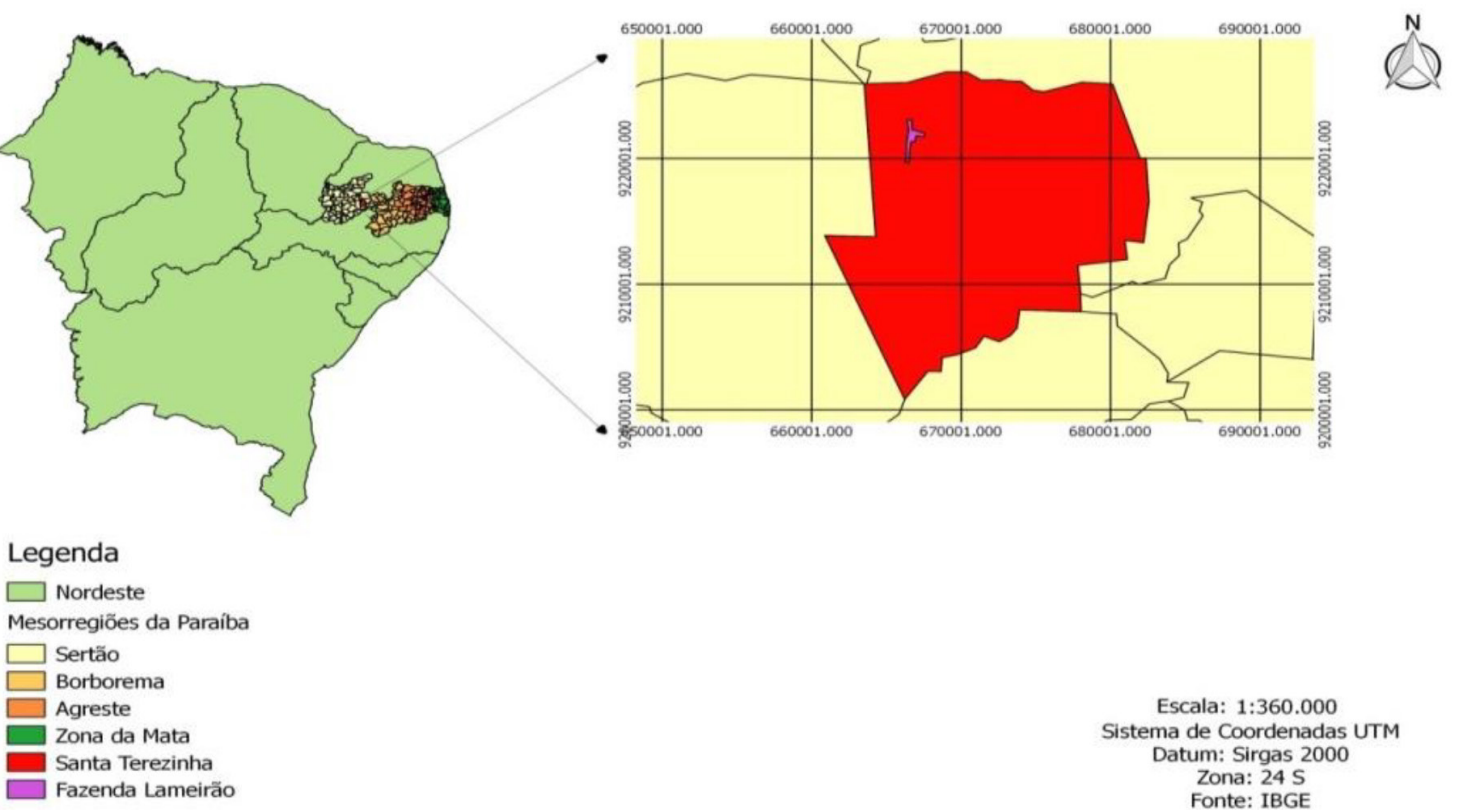

Escala: 1:360.000 Sistema de Coordenadas UTM Datum: Sirgas 2000 Zona: $24 \mathrm{~S}$

Fonte: Autores (2018)

A área de estudo possui 12 ha e a vegetação que a recobre é composta basicamente pelos estratos arbustivo-arbóreo e herbáceo, com espécies adaptadas às condições adversas do clima associado aos solos rasos e de superfície pedregosa com alta susceptibilidade à erosão e pouca capacidade de armazenamento de água, como a catingueira, Mimosa tenuiflora (Willd.) Poir. e o Croton sonderianus Muell.Arg. A área é constantemente submetida à extração de lenha para fins domésticos e manutenção dos cercados da fazenda, além do pastejo de caprino, ovino, bovino e asinino.

O regime pluviométrico histórico para o município de Santa Terezinha é bastante irregular, com médias anuais em torno de 839,1 mm (1911-1990), concentrado de fevereiro a abril com $72 \%$ da incidência de chuvas (UNIVERSIDADE FEDERAL DE CAMPINA GRANDE, 2017). Segundo a classificação climática, o clima da área é do tipo BSh - Semiárido quente, com baixa umidade relativa do ar e irregularidade pluviométrica no espaço e no tempo (ALVARES et al., 2014).

Na Figura 2, pode-seobservar a precipitação mensal histórica(1911-1990)(UNIVERSIDADE 
FEDERAL DE CAMPINA GRANDE, 2017) para o município de Santa Terezinha e a precipitação mensal para os anos de 2016 e 2017 na área de estudo. Os dados foram obtidos na própria fazenda. No ano de 2016, choveu 483,0 $\mathrm{mm}$ e $646,8 \mathrm{~mm}$ em 2017, concentrando-se entre os meses de janeiro a abril.

Figura 2 - Precipitação mensal histórica (1911-1990) para o município de Santa Terezinha e dos anos de 2016 e 2017 na área de estudo, Fazenda Lameirão, Santa Terezinha-PB, Brasil. Adaptado de Universidade Federal de Campina Grande (2017)

Figure 2 - Historical monthly precipitation for the municipality of Santa Terezinha and for the years 2016 and 2017 in the study area, Fazenda Lameirão, Santa Terezinha - Paraíba state, Brazil. Adapted from Universidade Federal de Campina Grande (2017)

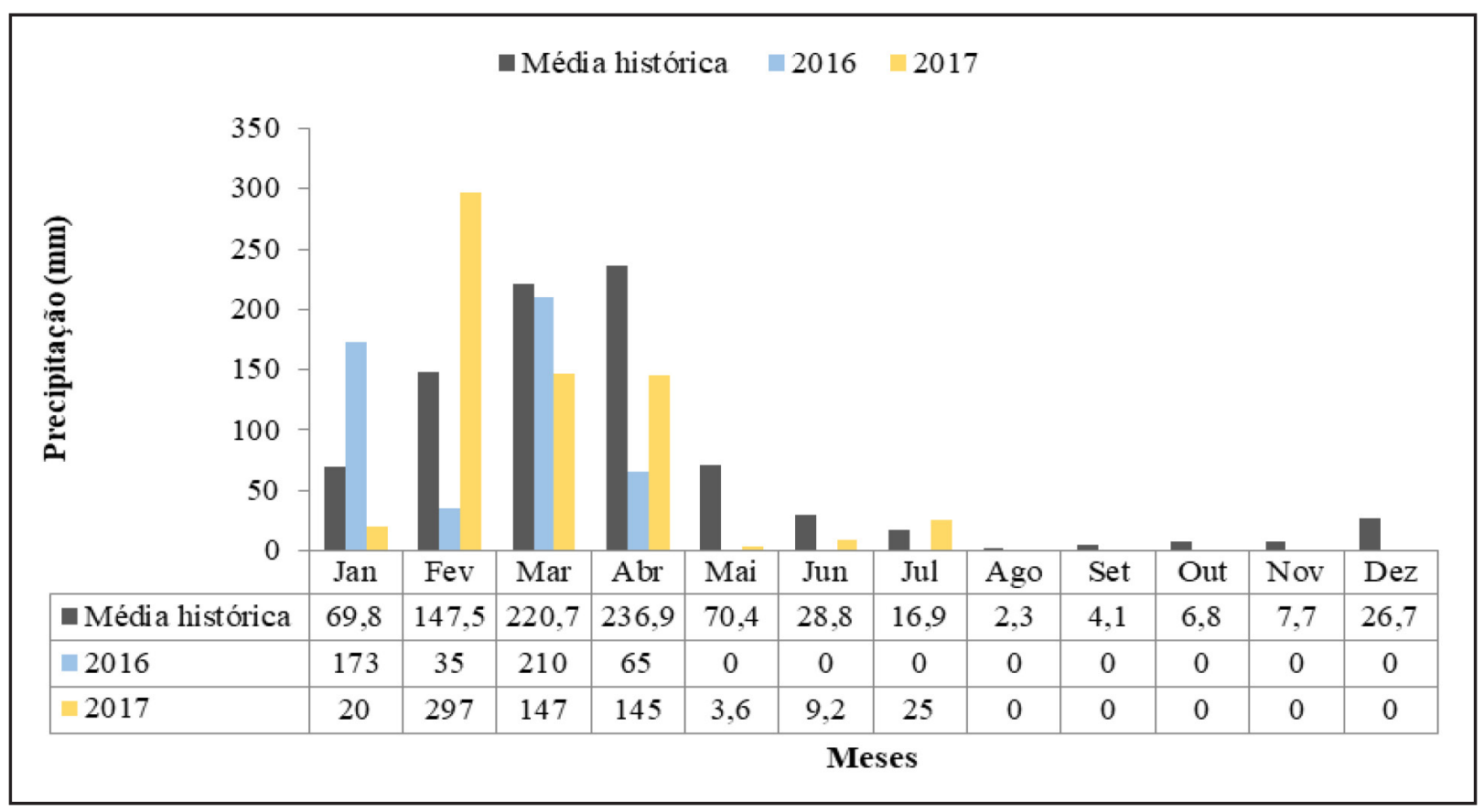

Fonte: Autores (2017)

\section{Coleta de dados}

Em abril de 2016, foi realizado o levantamento do número de indivíduos de catingueira por meio de amostragem sistemática em 24 unidades amostrais de $10 \mathrm{~m}$ x $20 \mathrm{~m}$ (RODAL; SAMPAIO; FIGUEIREDO, 2013), espaçadas 40 e 70 metros nas e entre linhas, respectivamente. Nessas unidades, foram mensurados todos os indivíduos da espécie que apresentaram altura total maior que $1,5 \mathrm{~m}$ e diâmetro a atura do peito $(\mathrm{DAP}) \geq 1,91 \mathrm{~cm}$ a $1,30 \mathrm{~m}$ do solo (REDE DE MANEJO FLORESTAL DA CAATINGA, 2005). A classificação taxonômica da espécie foi confirmada pelo Herbário CSTR da UFCG, campus de Patos, baseando-se no material vegetativo e fértil coletado no campo. Após o levantamento, foram calculados os parâmetros da estrutura horizontal (densidade, frequência e dominância), o Índice de Valor de Importância (IVI) para a espécie (Tabela 1), além da estrutura vertical (Figura 3). 
Tabela 1 - Parâmetros fitossociológicos de catingueira na área de estudo em fragmento de Caatinga, Fazenda Lameirão, Santa Terezinha-PB, Brasil

Table 1: Phytosociological parameters of catingueira in the study area in a Caatinga fragment, Fazenda Lameirão, Santa Terezinha-PB state, Brazil

\begin{tabular}{llllll}
\hline \multicolumn{1}{c}{ Espécies } & NI & DR & FR & DoR & IVI \\
\hline Poincianella pyramidalis (Tul.) L. P. Queiroz & 111 & 32,4 & 17,8 & 43,3 & 31,2 \\
Outras espécies & 343 & 67,6 & 82,2 & 56,7 & 68,8 \\
\hline
\end{tabular}

Fonte: Autores (2016)

Em que: NI = Número de Indivíduos; DR = Densidade Relativa (\%); FR = Frequência Relativa $(\%) ;$ DoR = Dominância Relativa (\%); IVI = Índice de Valor de Importância.

A partir disso, foram selecionadas 20 árvores adultas de catingueira. Cada árvore teve sua altura total e altura do fuste mensurado e, por subtração, foi obtida a altura da copa. As alturas totais das plantas variaram entre 3,6 e $5,5 \mathrm{~m}$ e o Diâmetro equivalente (Deq), obtido pela raiz quadrada da soma quadrática dos DAPs, variou de 13,86 a 31,83 cm. Cada árvore foi identificada no caule com tinta de cor vermelha e com etiqueta metálica contendo um número identificador.

Figura 3 - Distribuição do número de indivíduos de catingueira em classes de altura $(\mathrm{A})$ e diâmetro equivalente $(B)$

Figure 3: Distribution of the number of individuals of catingueira in classes of height (A) and equivalent diameter (B)

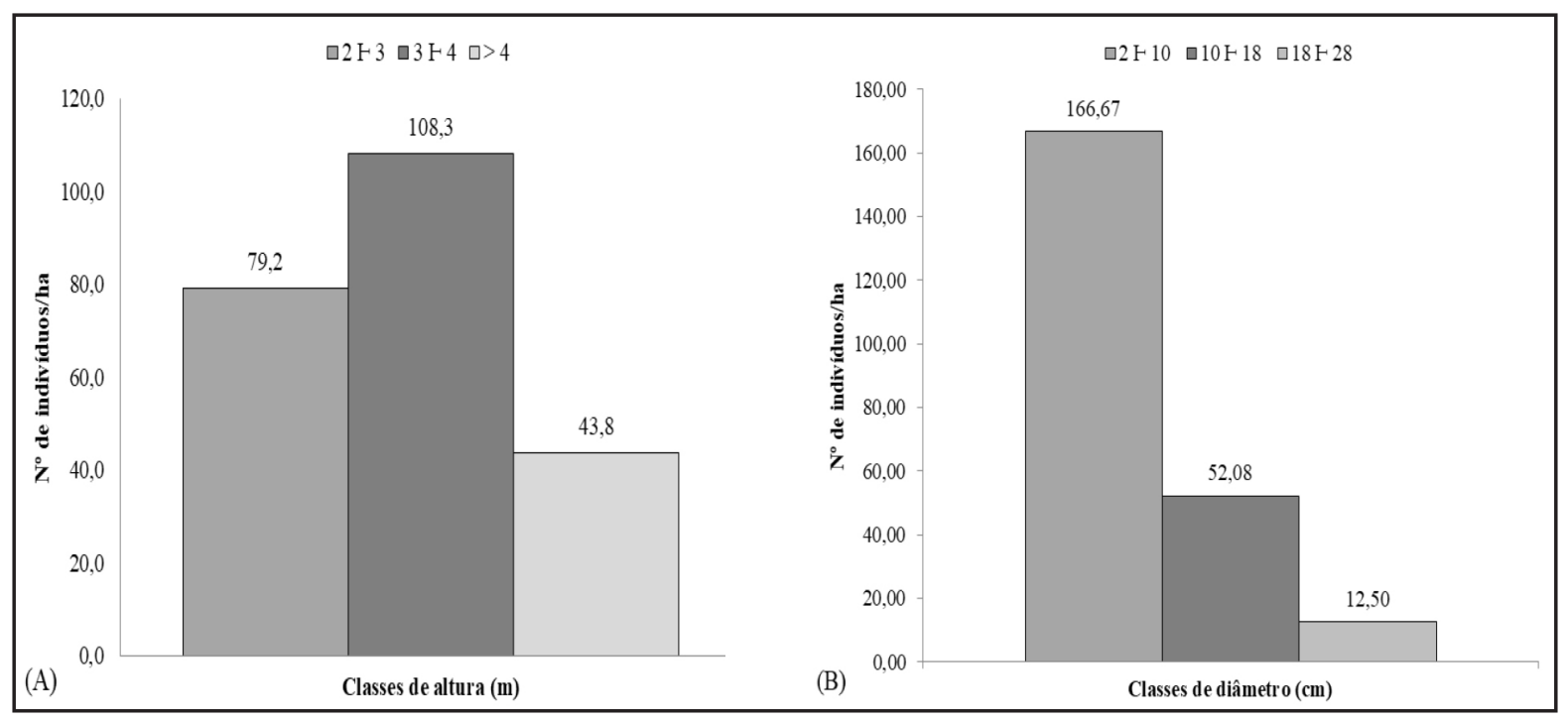

Fonte: Autores (2016) 
Os dados de Deq's foram coletados anualmente e inseridos em modelo volumétrico (SOARES; PAULA NETO; SOUZA, 2011) para estimar o volume cilíndrico de madeira de cada árvore e acúmulo de material lenhoso no período compreendido entre 2016 e 2017, onde:

$$
\mathrm{Vc}=\frac{\pi *\left(\mathrm{Deq}^{2}\right) * \mathrm{Ht}}{4}
$$

Em que: Vc = volume cilíndrico da árvore $\left(\mathrm{m}^{3}\right) ; \pi=3,1416 \ldots ;$ Deq = Diâmetro equivalente à Altura do Peito $(\mathrm{m})$; $\mathrm{Ht}=$ altura total da árvore (m).

O acúmulo de material lenhoso no período compreendido entre 2016 e 2017 foi obtido pela subtração do volume estimado para 2017 e 2016 para cada árvore, em que: Vc 2017 - Vc 2016.

O material forrageiro da parte aérea das plantas (ramas com até $10 \mathrm{~mm}$ de diâmetro) foi coletado com tesoura de poda de cabo de 1 metro de comprimento, até uma altura de aproximadamente 3 metros do solo à copa da árvore (Figura 4). O corte das ramas e obtenção dos dados ocorreu em abril de 2016 e abril de 2017, estação chuvosa na região, quando as plantas estavam em estágio vegetativo pleno.

A intensidade do corte das ramas de cada planta obedeceu aos seguintes tratamentos experimentais: $\mathrm{T} 1=$ testemunha, sem poda das ramas, $\mathrm{T} 2=25 \%, \mathrm{~T} 3=50 \%, \mathrm{~T} 4=75 \%$ e $\mathrm{T} 5=100 \%$ das ramas do perímetro da copa. Cada tratamento foi aplicado em 4 plantas, escolhidas aleatoriamente entre as 20 previamente identificadas, que tiveram altura total, de copa e Deq's semelhantes. Nas plantas submetidas ao T2, foram coletadas as ramas dos quadrantes sudeste; em T3, as ramas dos quadrantes sudeste e nordeste; nas submetidas ao T4, as ramas coletadas foram as dos quadrantes sudeste, nordeste e noroeste, e as submetidas ao T5 tiveram as suas ramas coletadas em todos os quadrantes. No ano de 2017, os cortes foram aplicados em cada planta nas mesmas intensidades; quadrante subsequente ao ano anterior em T2, nos dois quadrantes subsequentes em T3, em três quadrantes em T4 de modo que foram considerados dois quadrantes já podados no ano anterior e um quadrante que não havia sofrido corte, e novamente em todos os quadrantes em T5 (Figura 4).

Figura 4 - Demonstrativo de orientação nos pontos de coleta das ramas da copa das árvores de catingueira. (A) Vista transversal; (B) Vista Longitudinal

Figure 4 - Orientation demonstration at the collection points of the tree canopy branches of catingueira. (A) Cross view; (B) Longitudinal View

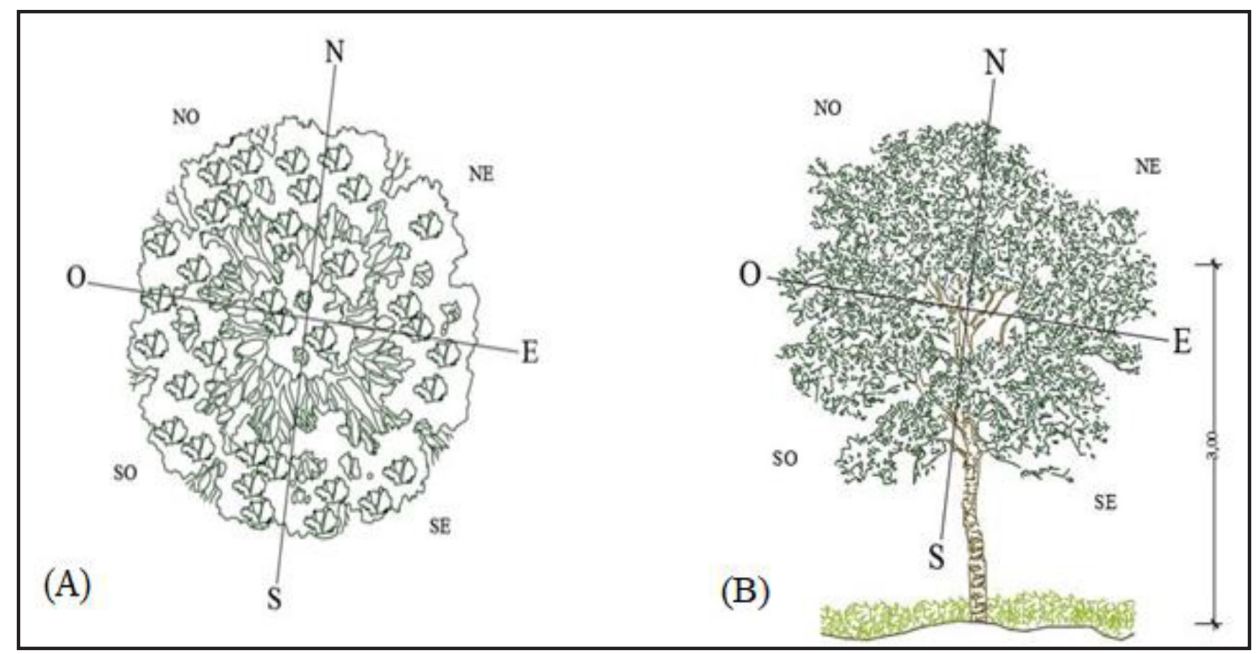

Fonte: Autores (2018) 
Dados de produção de forragem do estrato herbáceo sob e fora da projeção da copa de cada planta foram coletados momentos antes da poda das ramas. Para tanto, foi lançado, aleatoriamente, um gabarito de madeira com dimensões de $50 \mathrm{~cm} \times 50 \mathrm{~cm}$, sob e fora dos limites da projeção da copa no solo, sendo coletado todo o material herbáceo dentro dos limites internos do gabarito.

Para a estimativa da biomassa proveniente da poda das ramas de cada árvore de catingueira e do estrato herbáceo, foi utilizada a equação proposta por Soares e Oliveira (2002), onde:

$$
\operatorname{MST}=\frac{\text { MFT. MS (a) }}{\text { MF (a) }}
$$

Em que: MST = massa seca total (g); MFT = massa fresca da amostra (g); MS (a) = massa seca da amostra $(\mathrm{g})$ e $\operatorname{MF}(\mathrm{a})=$ massa fresca da $\operatorname{amostra}(\mathrm{g})$.

As ramas e o material herbáceo coletado foram pesados em balança digital de precisão de $2 \mathrm{~g}$, triturados e amostrados para análises bromatológicas. Para determinação do teor de Matéria Seca, as amostras obtidas foram pesadas, secas em estufa com circulação forçada de ar a $65^{\circ} \mathrm{C}$ e novamente pesadas após $72 \mathrm{~h}$ ou até obtenção de peso constante. A amostra seca foi processada em moinho com peneira de $1,0 \mathrm{~mm}$ e acondicionada em frascos plásticos identificados de acordo com cada tratamento para posterior determinação dos teores de Fibra em Detergente Neutro e Ácido (FDN e FDA), Proteína Bruta (PB) e Cinzas, na base da Matéria Seca (MS) a 65드, no Laboratório de Nutrição Animal do Centro de Saúde e Tecnologia Rural da UFCG, Patos - PB, conforme método descrito por Silva e Queiroz (2002).

O delineamento experimental foi o inteiramente casualizado (DIC) com cinco tratamentos $(\mathrm{T} 1=$ testemunha, sem poda das ramas, $\mathrm{T} 2=25 \%, \mathrm{~T} 3=50 \%, \mathrm{~T} 4=75 \%$ e $\mathrm{T} 5=100 \%)$ com quatro repetições de uma árvore para as variáveis altura e circunferência de copa, diâmetro a altura do peito (DAP) e volume $\left(\mathrm{m}^{3}\right)$ do fuste. Os dados de produção de forragem arbórea (kg/árvore) tiveram o DIC com quatro tratamentos $(\mathrm{T} 2=25 \%$, T3 $=50 \%, \mathrm{~T} 4=75 \%$ e $\mathrm{T} 5=100 \%$ de poda das ramas do perímetro da copa) com quatro repetições de uma árvore.

Os dados de produção de forragem herbácea $\left(\mathrm{kg} / 0,25 \mathrm{~m}^{2}\right)$ foram coletados em abril de 2016 e abril de 2017. Em 2016, foram coletados dados sob e fora da copa de seis árvores. Esses dados foram considerados em conjunto com mais quatro plantas coletadas em 2017, de acordo com um delineamento inteiramente casualizado com dois tratamentos (T1 = produção de forragem sob a copa de catingueira, e T2 = produção de forragem fora da influência da copa da catingueira) e 10 repetições. Os dados de produção de forragem herbácea coletados em abril de 2017 sob a copa dos 20 indivíduos de catingueira foram analisados utilizando um delineamento inteiramente casualizado com 5 tratamentos ( $\mathrm{T} 1$ = testemunha, sem poda das ramas, e poda de $\mathrm{T} 2=25 \%$, $\mathrm{T} 3=$ $50 \%, \mathrm{~T} 4=75 \%$ e $\mathrm{T} 5=100 \%$ das ramas do perímetro da copa) e quatro repetições, e serviram para testar o efeito da intensidade da poda das ramas na produção de forragem do estrato herbáceo sob a copa dos indivíduos desta espécie.

O nível de significância adotado foi de 5\%. Quando detectados problemas de heterocedasticidade entre as variâncias de tratamentos, os dados foram log-transformados e analisados. Porém, os dados no texto e nas tabelas foram sempre expostos em escala original, tanta para análises realizadas utilizando dados em escala original ou log-transformados (STATSOFT, 1999). 


\section{Resultados e discussão}

Não foram detectadas diferenças significativas no incremento do diâmetro equivalente (Deq) e no volume de madeira entre as árvores submetidas às cinco intensidades de poda $(\mathrm{p}>0,05)$ (Tabela 2). Isso indica, de uma maneira geral, que os indivíduos de catingueira suportam bem a primeira poda das suas ramas periféricas no que se refere ao acúmulo anual de material lenhoso, a despeito do baixo nível de precipitação verificado em 2016 (483 mm). Essa baixa precipitação foi compensada, em parte, pela razoável precipitação verificada entre janeiro e abril de 2017 (609,00 $\mathrm{mm}$ ). Esses resultados são satisfatórios para os produtores que visam à produção conjunta de lenha e forragem desta espécie.

Tabela 2 - Incremento no Diâmetro equivalente (Deq) e acúmulo de biomassa lenhosa, e respectivas variações anuais de indivíduos de catingueira submetidos a cinco intensidades de poda de suas ramas periféricas, Fazenda Lameirão, Santa Terezinha-PB, Brasil

Table 2 - Increase in the equivalent diameter (Deq) and accumulation of woody biomass, and respective annual variations, of catingueira submitted to five pruning intensities of its peripheral branches, Fazenda Lameirão, Santa Terezinha - Paraíba, Brazil

\begin{tabular}{|c|c|c|c|c|c|c|}
\hline \multirow{2}{*}{ Intensidades de poda } & \multicolumn{2}{|c|}{$\operatorname{Deq}(\mathbf{c m})$} & \multirow{2}{*}{ Variação anual (\%) } & \multicolumn{2}{|c|}{ Biomassa lenhosa $\left(\mathbf{m}^{\mathbf{3}}\right)$} & \multirow{2}{*}{ Variação anual (\%) } \\
\hline & 2016 & 2017 & & 2016 & 2017 & \\
\hline 0\% & 18,83 & 18,99 & $0,84 a^{*}$ & 0,499 & 0,531 & $6,41 \mathrm{a}$ \\
\hline $25 \%$ & 20,28 & 20,42 & $0,68^{\underline{a}}$ & 0,526 & 0,558 & $6,08 \mathrm{a}$ \\
\hline $50 \%$ & 19,24 & 19,3 & $0,32^{\underline{a}}$ & 0,492 & 0,527 & $7,11 \mathrm{a}$ \\
\hline $75 \%$ & 19,34 & 19,45 & $0,56^{\underline{a}}$ & 0,535 & 0,577 & $7,85 a$ \\
\hline $100 \%$ & 23,84 & 24,09 & $1,04^{\underline{a}}$ & 0,874 & 0,944 & $8,01 \mathrm{a}$ \\
\hline
\end{tabular}

Fonte: Autores (2017)

Em que: *Médias nas colunas seguidas de mesma letra são semelhantes pelo teste F da ANOVA (p>0,05).

Bakke et al. (2007) verificaram resultado contrário ao deste trabalho após a poda anual (2002-2003-2004) e consecutiva de 100\% das ramas da copa de Mimosa tenuiflora (Willd.) Poir., quando a precipitação anual totalizou, respectivamente, 770,60, 543,50 e 746,50 mm.ano-1. Nesse período, o acúmulo de biomassa lenhosa se reduziu a aproximadamente $50 \%$ e $0 \%$ do observado nas plantas não podadas após a primeira e a segunda poda, respectivamente, ocorrendo à morte das plantas quando o procedimento se repetiu pela terceira vez, o que certamente poderá ocorrer com os indivíduos de catingueira.

De acordo com Davidson e Milthorpe (1966), a diminuição na produção e ou no acúmulo de biomassa pode variar com a intensidade da desfolha, pois a redução na área foliar diminui a interceptação da radiação solar que incide sobre a planta, afetando a produção de fotoassimilados. Portanto, são necessários estudos adicionais a respeito de quantos cortes anuais consecutivos as plantas de catingueira suportam sem afetar sua produção de ramas e acúmulo de biomassa lenhosa.

A produção média de forragem arbórea (kg/árvore) diminuiu do primeiro para o segundo corte, notadamente para as intensidades de poda de $75 \%$ e $100 \%$, quando essa redução saltou de $30-40 \%$ para mais de $75 \%(\mathrm{p}<0,05)$ (Tabela 3). Extrapolando essa produção para o hectare, considerando apenas a quantidade de plantas da terceira classe diamétrica (Figura 3 B; 12,50 planta/ha) determinada no levantamento fitossociológico, as quais melhor representam as plantas submetidas às cinco intensidades de poda no experimento, temos uma produção anual 
de forragem de catingueira variando de 27,40 a $88,40 \mathrm{~kg}$ de $\mathrm{MS}$, na primeira poda, e de 13,30 a $30,10 \mathrm{~kg}$ de MS, na segunda poda. O potencial real de produção de forragem para a espécie é certamente maior, visto que não foram considerados os estimados 218 indivíduos menores alocadas nas duas primeiras classes diamétricas (Figura $3 \mathrm{~B}$ ).

\section{Tabela 3 - Quantidade e respectiva variação anual na produção de forragem (matéria fresca e seca), em dois anos consecutivos, proveniente das ramas periféricas de catingueira, de acordo com quatro intensidades de poda, Fazenda Lameirão, Santa Terezinha-PB, Brasil}

Table 3 - Quantity and respective annual variation in forage production (fresh and dry matter), in two consecutive years, coming from the peripheral branches of catingueira, according to four pruning intensities, Fazenda Lameirão, Santa Terezinha - PB state, Brazil

\begin{tabular}{|c|c|c|c|c|c|c|}
\hline \multirow{2}{*}{ Intensidades de poda } & \multicolumn{2}{|c|}{$\begin{array}{c}\text { Matéria fresca } \\
\text { (kg/árvore) }\end{array}$} & \multirow{2}{*}{ Variação anual (\%) } & \multicolumn{2}{|c|}{$\begin{array}{c}\text { Matéria Seca } \\
\text { (kg/árvore) }\end{array}$} & \multirow{2}{*}{ Variação anual (\%) } \\
\hline & 2016 & 2017 & & 2016 & 2017 & \\
\hline $25 \%$ & $3,39 \mathrm{c}$ & 2,43 & $-28,33 a^{*}$ & 2,19 & 1,33 & $-39,32 \mathrm{a}$ \\
\hline $50 \%$ & $5,89 \mathrm{bc}$ & 3,92 & $-33,46^{\underline{a}}$ & 3,79 & 2,41 & $-36,58 \mathrm{a}$ \\
\hline $75 \%$ & $11,27 \mathrm{a}$ & 2,71 & $-75,98 b$ & 7,07 & 1,48 & $-79,11 b$ \\
\hline $100 \%$ & $9,53 \mathrm{ab}$ & 1,94 & $-79,67 b$ & 5,78 & 1,06 & $-81,72 b$ \\
\hline
\end{tabular}

Fonte: Autores (2017)

Em que: *Médias nas colunas seguidas de mesma letra são semelhantes pelo teste $\mathrm{F}$ da $\operatorname{ANOVA}(\mathrm{p}<0,05)$.

A redução na produção de forragem arbórea no segundo ano evidencia o estresse provocado nas plantas pela poda das ramas periféricas, especialmente quando $75 \%$ e $100 \%$ das ramas periféricas foram podadas, como constatado anteriormente. A provável explicação para essa redução é que as reservas nutricionais das plantas se exauriram do primeiro (2016) para o segundo ano (2017). Desse modo, no segundo ano, houve desfavorecimento da rebrota e redução da área foliar da copa e da produção de fotoassimilados (CARVALHO et al., 1998). Outro fator que pode ter afetado a menor produção no segundo ano foi o baixo nível de precipitação em 2016 como um todo $(483 \mathrm{~mm})$ e praticamente ausência de precipitação no restante dos meses do ano após a poda (i.e.: entre abril e dezembro de 2016). Tal fato não permitiu a recomposição das reservas nutritivas pelas plantas podadas e resultou na sua brotação menos vigorosa e mais tardia, observada apenas no final de março e início de abril de 2017.

Alves (2011) estimou em $100 \mathrm{~kg} \cdot \mathrm{ha}^{-1}$ a biomassa foliar fresca de Piptadenia moniliformis Benth.; 100 kg.ha-1 para Jatropha molissima L.; 300 kg.ha-1 para Mimosa ophtalmocentra Mart. ex Benth. e $1.300 \mathrm{~kg} \cdot \mathrm{ha}^{-1}$ para Poincianella bracteosa (Tul.) L.P. Queiroz, em área de caatinga em regeneração, em Floresta/PE. Esses valores ficam ainda mais expressivos na área de caatinga conservada, notadamente para Poincianella bracteosa (Tul.) L.P. Queiroz, que atinge $3.000 \mathrm{~kg}$ de biomassa foliar por hectare. Araújo, Leite e Paes (2004) e Bakke et al. (2007) estimaram que a produção foliar de Mimosa tenuiflora (Willd.) Poir. pode superar os $5.800 \mathrm{~kg}$.ha ${ }^{-1}$, no município de Patos/PB. Porém, Bakke et al. (2007) recomendam que o corte anual das ramas seja efetuado no início da estação seca e que entre uma poda e outra seja cumprido um prazo mínimo, que pode ser de mais de um ano, para as plantas recomporem suas reservas. Vale esclarecer, porém, que a superioridade de valores reportados na literatura deve ser vista com cautela, pois em parte é devida à inclusão da biomassa foliar de todos os indivíduos das espécies lenhosas acima mencionadas, enquanto no presente estudo apenas aqueles com Deq $>18 \mathrm{~cm}$ foram considerados.

Assim, a coleta das ramas finas das espécies lenhosas forrageiras da caatinga na fase 
de vegetação plena para fenação e oferecimento aos animais na estação seca no semiárido nordestino, incluindo catingueira, deve ser considerada diante da escassez de alimento nessa época. Isso se justifica pelo fato de que várias espécies arbóreas da caatinga são consumidas pelos animais. No Cariri paraibano, por exemplo, as folhas naturalmente fenadas de catingueira e de Croton sonderianus Muell.Arg. quando caem ao solo constituem importante fonte de forragem para caprinos na estação seca, participando, respectivamente, com 12,50\% e 25,00\% da dieta desses animais (LEITE; VIANA, 1986). Em Sobral (CE), as folhas secas de espécies arbóreas atingem 38,10 e $22,30 \%$ da dieta de ovinos e caprinos, respectivamente (PFISTER; MALECHEK, 1986). Há autores que estimam uma participação ainda maior das espécies arbóreas na dieta de ruminantes. Araújo Filho (2013) estima que a dieta média anual de caprinos, ovinos e bovinos pode ser constituída de até $86,80 \%, 77,60 \%$ e $70,10 \%$, respectivamente, de material forrageiro de origem arbustivo-arbórea.

A produção de forragem herbácea, na base da MS, foi maior sob $\left(1,60\right.$ t.ha $\left.^{-1}\right)$ do que fora da projeção da copa $\left(1,07\right.$ t.ha $\left.^{-1}\right)$ de catingueira $(\mathrm{P}<0,05)$ (Tabela 4). Esses resultados indicam o efeito positivo do componente arbustivo-arbóreo no manejo florestal da caatinga para fins agrosilvipastoris. Isso já foi recomendado por Araújo Filho (2013), que aconselha $30 \%$ a $40 \%$ de cobertura do solo pela copa das árvores. O autor explica que a presença do componente arbóreo em pastagens da caatinga não prejudica a produção de forragem do estrato herbáceo, tem a vantagem de proteger o solo da radiação solar e da erosão provocada pelo vento e chuva, fornece sombra para os animais, melhora as condições para o desenvolvimento da fauna edáfica e do sistema radicular das plantas, além de produzir ramas forrageiras e biomassa lenhosa.

\section{Tabela 4 - Médias de produção de biomassa $\left(t \cdot h a^{-1}\right)$ do estrato herbáceo sob e fora da projeção da copa de indivíduos de catingueira, Fazenda Lameirão, Santa Terezinha-PB, Brasil}

Table 4 - Averages of biomass production $\left(\mathrm{t} \mathrm{ha}^{-1}\right)$ of the herbaceous stratum under and outside the crown projection of catingueira, Fazenda Lameirão, Santa Terezinha - PB state, Brazil

\begin{tabular}{ccc}
\hline \multicolumn{1}{c}{ Tratamentos } & Matéria fresca & Matéria seca \\
\hline Sob a copa & $4,92 \mathrm{a}$ & $1,60 \mathrm{a}$ \\
Fora da projeção da copa & $2,89 \mathrm{~b}$ & $1,07 \mathrm{~b}$ \\
\hline
\end{tabular}

Fonte: Autores (2017)

Em que: *Médias, nas colunas, seguidas da mesma letra não diferem entre si pelo teste $\mathrm{F}$ da ANOVA $(p>0,05)$.

As variações na produção de biomassa herbácea na caatinga estão fortemente relacionadas com a precipitação anual observada em cada área do bioma, e outros fatores como os diferentes níveis de antropização. Silva et al. (1999) verificaram que a produção de biomassa herbácea, obtida na Fazenda Experimental Crioula, Embrapa Caprinos, Sobral-CE, foi de 2,40 t.ha' de $^{-1}$ SS em um ano em que a precipitação foi de $432,00 \mathrm{~mm}$, e aumentou para 4,10 t.ha ${ }^{-1}$ de MS no ano seguinte quando a precipitação anual totalizou $1.449,00 \mathrm{~mm}$. Em caatinga raleada, a produção de forragem herbácea pode chegar a 5,0 t.ha-1 (MS) (SILVA et al., 1999; CARVALHO et al., 2001). Figueiredo (2017), em caatinga antropizada da Fazenda Nupeárido-UFCG, em Patos-PB, verificou produção de biomassa forrageira herbácea de 3,00 t.ha $^{-1}$ (MS) quando a precipitação atingiu $1.657 \mathrm{~mm}$ no ano de 2009 , com composição de $42 \%$ de monocotiledôneas e $58 \%$ de dicotiledôneas.

Não houve efeito da intensidade da poda das ramas na produção de forragem herbácea sob a copa de catingueira $(p>0,05)$ (Tabela 5). Isso indica que as alterações ambientais resultantes da poda das ramas periféricas como, por exemplo, a variação no grau de sombreamento do solo, 
não foi suficiente para prejudicar o estrato herbáceo sob a copa das árvores podadas.

Tabela 5 - Produção de forragem herbácea $\left(t \cdot \mathrm{ha}^{-1}\right)$ sob a copa de indivíduos de catingueira um ano após serem submetidas a cinco intensidades de poda de suas ramas periféricas, Fazenda Lameirão, Santa Terezinha-PB, Brasil

Table 5 - Herbaceous forage production $\left(\mathrm{t}_{\mathrm{h}} \mathrm{h}^{-1}\right)$ under the crown of catingueira one year after being submitted to five pruning intensities of its peripheral branches, Fazenda Lameirão, Santa Terezinha - PB state, Brasil

\begin{tabular}{lcc}
\hline Intensidade de poda & Matéria fresca & Matéria seca \\
\hline $\mathbf{0} \%$ & $6,29 \mathrm{a}^{*}$ & $1,95 \mathrm{a}$ \\
$\mathbf{2 5} \%$ & $4,18 \mathrm{a}$ & $1,90 \mathrm{a}$ \\
$\mathbf{5 0} \%$ & $2,77 \mathrm{a}$ & $1,08 \mathrm{a}$ \\
$\mathbf{7 5 \%}$ & $4,96 \mathrm{a}$ & $1,74 \mathrm{a}$ \\
$\mathbf{1 0 0} \%$ & $4,04 \mathrm{a}$ & $1,52 \mathrm{a}$ \\
\hline
\end{tabular}

Fonte: Autores (2017)

Em que: *Médias nas colunas seguidas de mesma letra não diferem entre si pelo teste F da ANOVA $(p>0,05)$.

Os teores de MS para a forragem de catingueira foram de $62,46 \%$ em 2016 e de 55,84\% em 2017 (Tabela 6). Essa diminuição do teor de MS em 2017 da forragem de catingueira provavelmente ocorreu devido à coleta de material mais tenro em 2017 por conta do atraso do enfolhamento verificado nesse ano se comparado ao ano anterior. Araújo Filho (2013) e Aguiar et al. (2014) reportaram teores crescentes de MS nas folhas e nas ramas de catingueira da fase de vegetação plena para a de dormência: de $45,40 \%$ a 87,10 . Para a forragem herbácea, o teor de MS foi de $36,72 \%$.

Tabela 6 - Composição bromatológica das ramas de catingueira e da biomassa forrageira do estrato herbáceo, Fazenda Lameirão, Santa Terezinha-PB, Brasil

Table 6 - Bromatological composition of the branches of catingueira and forage biomass of the herbaceous stratum, Fazenda Lameirão, Santa Terezinha - PB state, Brazil

\begin{tabular}{lccc}
\hline \multirow{2}{*}{ Composição (\%) } & \multicolumn{2}{c}{ Forragem arbórea } & \multirow{2}{*}{ Forragem herbácea } \\
\cline { 2 - 3 } & $\mathbf{2 0 1 6}$ & $\mathbf{2 0 1 7}$ & \\
\hline MS & 62,46 & 55,84 & 36,72 \\
PB & 12,66 & 12,50 & 9,60 \\
FDN & 50,23 & 44,82 & 37,94 \\
FDA & 36,46 & 31,99 & 27,97 \\
CZ & 6,55 & 6,81 & 9,78 \\
MO & 93,45 & 93,19 & 90,22 \\
\hline
\end{tabular}

Fonte: Autores (2017)

Em que: $\mathrm{MS}=$ matéria seca $\mathrm{PB}=$ proteína bruta FDN = Fibra em detergente neutro; FDA = Fibra em detergente ácido; $\mathrm{CZ}$ = cinzas; $\mathrm{MO}=$ matéria orgânica. 
Os teores de $\mathrm{PB}$ foram superiores a $12 \%$ nas ramas de catingueira e atingiram 9,60\% para a forragem herbácea. Esses teores de $\mathrm{PB}$ das ramas desta espécie podem estar relacionados à fase vegetativa das plantas (meio da estação chuvosa da região) e superam o mínimo necessário (7\%) em uma dieta de manutenção de ruminantes (VAN SOEST, 1994). Porém, os teores de PB das ramas de catingueira foram inferiores aos $16,90 \%$ reportados para as folhas desta espécie por Araújo Filho (2013), na fase de vegetação plena, certamente pela diferença do material analisado (ramas vs. folhas). O teor de PB encontrado para a biomassa forrageira herbácea neste estudo foi 9,60\%, semelhante aos 9,10\% de PB observados por Santana et al. (2011), em Serra Talhada-PB, que situam-se acima do mínimo necessário para os ruminantes.

Os teores de FDN e FDA, observados nas ramas periféricas de catingueira coletadas em 2016 , foram de $50,23 \%$ e $36,46 \%$, respectivamente e em 2017 reduziram para $44,82 \%$ e 31,99\%, respectivamente. Essa redução pode ter ocorrido devido ao material colhido em 2016 não ter sofrido cortes de anos anteriores, enquanto que em 2017 o material colhido teve apenas um ano de crescimento. Os teores de fibra presentes nas folhas de catingueira podem variar de 31,90 a 49,80\% em FDN e os da FDA entre 19,80 a 37,08\% nas fases de vegetação plena e após a senescência, respectivamente (GONZAGA NETO; BATISTA; CARVALHO, 2001; ZANINE et al., 2005; DAMASCENO, 2007; MENDONÇA JUNIOR; BRAGA; GALVÃO, 2008; SOUZA et al., 2013; AGUIAR et al., 2014).

Os teores de fibras na forragem herbácea de uma amostra composta dessa forragem coletada em 2016 e em 2017, sob e fora a projeção da copa de catingueira, foram de $37,94 \%$ para a FDN e de $27,97 \%$ para FDA. Valores superiores a esses foram observados por Santana et al. (2011), que reportaram teores que variaram de $68,45 \%$ a $71,43 \%$ para $F D N$, e de $56,23 \%$ a $55,93 \%$ para a FDA, entre os meses de março e julho de 2003. Formiga et al. (2011) verificaram valores mais expressivos em material forrageiro coletado entre junho e outubro: FDN variando de $61,80 \%$ a $82,4 \%$, e FDA de $55,9 \%$ a $79,8 \%$ nas dicotiledôneas herbáceas, e FDN variando de $81 \%$ a $84,4 \%$, e a FDA de $75,0 \%$ a $81,7 \%$ nas monocotiledôneas, em Caatinga raleada pastejada por ovinos e caprinos em área vizinha à deste trabalho. Os níveis de fibra, relativamente baixos, reportados no presente estudo, mostram que os materiais arbóreo e herbáceo coletados são relativamente pouco fibrosos, de qualidade razoável e apropriados para a alimentação de ruminantes.

Os teores de CZ foi de 6,55\% para forragem arbórea e 9,78\% para herbácea e os teores de $\mathrm{MO}$ mantiveram-se acima de $90 \%$ para ambas as forragens. Esses valores de CZ e MO para catingueira são semelhantes aos relatados por Gonzaga Neto, Batista e Carvalho (2001) para as folhas desta espécie: 6,11\% para CZ e 93,89\% para MO.

Os resultados para a forragem de catingueira sugerem a possibilidade da utilização estratégica desta forrageira na alimentação animal na região semiárida do nordeste brasileiro (MENDONÇA JUNIOR; BRAGA; GALVÃO, 2008; AGUIAR et al., 2014), especialmente no município de Santa Terezinha-PB, onde a espécie é abundante e apresenta-se com mais de $80 \%$ dos indivíduos de catingueira com baixa estatura (altura e diâmetro), o que facilita a coleta de suas ramas através da poda. 


\section{Conclusões}

A poda das ramas de catingueira resultou em 2,19 e 5,78 $\mathrm{kg}$ de matéria seca por árvore para as intensidades de poda de $25 \%$ e $100 \%$, respectivamente, na primeira coleta, e diminuiu entre 30 e $80 \%$ na segunda coleta, notadamente nas intensidades de poda de $75 \%$ e $100 \%$ das ramas.

A poda de até $100 \%$ das ramas de catingueira não afetou o incremento do diâmetro a altura do peito e o acúmulo de biomassa lenhosa das plantas durante o período de avaliação.

A composição química da forragem das ramas de catingueira é adequada para a alimentação animal.

A produção de forragem herbácea é maior sob do que fora da projeção da copa de catingueira.

As intensidades da poda das ramas das árvores de catingueira não afetou a produção da forragem herbácea sob a copa.

\section{Referências}

AGÊNCIA EXECUTIVA DE GESTÃO DAS ÁGUAS. Relatório anal sobre a situação dos recursos hídricos no Estado da Paraíba. Ano hidrológico 2008-2009. [S. l., 2009]. Disponível em: http://www.aesa.pb.gov.br/aesa-website/documentos/relatorios/relatorio-hidrologico/. Acesso em: 18 dez. 2017.

AGUIAR, E. M. et al. Avaliação bromatológica da catingueira no semiárido potiguar. Revista Centauro, Natal, v. 5, n. 1, p. 13-20, 2014.

ALMEIDA, J. R.; AQUINO, A. R.; AGUIAR, L. A. Avaliação do uso dos recursos florestais para fins energéticos pela população rural de São Jose do Mipibu - (RN-Brasil). Revista Brasileira de Pesquisa e Desenvolvimento, São Paulo, v. 5, n. 23, p. 101-105, 2003.

ALVES, A. R. Quantificação de biomassa e ciclagem de nutrientes em áreas de vegetação de caatinga no município de Floresta, Pernambuco. 2011. Tese (Doutorado em Ciências Florestais) - Universidade Federal Rural de Pernambuco, Departamento de Engenharia Florestal, Recife, 2011.

ALVARES, C. A. et al. Köppen's climate classification map for Brazil. Meteorologische Zeitschrift, Stuttgart, v. 22, n. 6, p. 711-728, 2014.

ARAÚJO FILHO, J. A. Manejo pastoril sustentável da caatinga. Recife: Projeto Dom Helder Câmara, 2013.

ARAÚJO, L. V. C.; LEITE, J. A. N.; PAES, J. B. Estimativa da produção de biomassa de um povoamento de jurema-preta Mimosa tenuiflora (Willd.) Poiret. com cinco anos de idade. Biomassa \& Energia, Viçosa, MG, v. 1, n. 4, p. 347-352, 2004.

BAKKE, I. A. et al. Forage yield and quality of a dense thorny and thornless "jurema-preta" stand. Pesquisa Agropecuária Brasileira, Brasília, v. 42, n. 3, p. 341-347, 2007.

CARVALHO, F. C. et al. Efeito do corte da parte aérea na sobrevivência do marmeleiro (Croton Sonderianus Muell.Arg.). Revista Brasileira de Zootecnia, Viçosa, MG, v. 30, n. 3, p. 930-934, 2001.

CARVALHO, F. C. et al. Flutuações dos níveis dos carboidratos de reserva disponíveis nas raízes e no caule do marmeleiro (Croton sonderianus Muell. Arg.). Revista Brasileira de Zootecnia, Viçosa, MG, v. 27, n. 4, p. 670-675, 1998.

COSTA, M. R. G. et al. Utilização do feno de forrageiras lenhosas nativas do Nordeste brasileiro 
na alimentação de ovinos e caprinos. Pubvet, Maringá, v. 5, n. 7, 2011.

DAMASCENO, M. M. Composição bromatológica de forragem de espécies arbóreas da caatinga paraibana em diferentes altitudes. 2007. Dissertação (Mestrado em Zootecnia) Universidade Federal de Campina Grande Centro de Saúde e Tecnologia Rural, Programa de Pós-Graduação em Zootecnia, Patos-PB, 2007.

DAVIDSON, J. L.; MILTHORPE, F. L. The effect of defoliation on the carbon balance in dactylis glomerata. Annals of Botany, Oxford, v. 30, n. 118, 1966.

DRUMOND, M. A. et al. Estratégias para o Uso Sustentável da Biodiversidade da Caatinga. In: SEMINÁRIO "BIODIVERSIDADE DA CAATINGA", 2000, Petrolina. Anais [...]. Petrolina: EMBRAPA Semiárido, 2000. Disponível em http://www.uep.cnps.embrapa.br/solos/index. php?link=pb. Acesso: 12 jul. 2016.

FIGUEIREDO, J. M. et al. Regeneração herbácea em áreas degradadas de caatinga enriquecidas com árvores nativas. Ciência Florestal, Santa Maria, v. 27, n. 4, p. 1143-1156, 2017.

FORMIGA, L. D. A. S. et al. Valor nutritivo da vegetação herbácea de caatinga enriquecida e pastejada por ovinos e caprinos. Revista Brasileira de Saúde e Produção Animal, Salvador, v. 12, n. 2, p. 403-415, 2011.

FRANCELINO, M. R. et al. Contribuição da caatinga na sustentabilidade de projetos de assentamentos no sertão norte-rio-grandense. Revista Árvore, Viçosa, MG, v. 27, n. 1, p. 79-86, 2003.

GONZAGA NETO, S.; BATISTA, A. M. V.; CARVALHO, F. F. R. Composição bromatológica, consumo e digestibilidade in vivo de dietas com diferentes níveis de feno de catingueira (Caesalpinia bracteosa), fornecidas para ovinos Morada Nova. Revista Brasileira de Zootecnia, Viçosa, MG, v. 30, n. 2, p. 553-562, 2001.

IBGE. Manual técnico de pedologia. 2. ed. Rio de Janeiro, 2010. Disponível em http://biblioteca. ibge.gov.br/visualizacao/livros/liv37318.pdf. Acesso em: 25 ago. 2017.

LEITE, E. R.; VIANA, J. J. Avaliação do potencial forrageiro nos Cariris paraibanos. In: REUNIÃO ANUAL DA SOCIEDADE BRASILEIRA DE ZOOTECNIA, 23., 1986, Campo Grande. Anais [...]. Campo Grande: Sociedade Brasileira de Zootecnia, 1986. p. 229.

LIMA JÚNIOR, V. Caracterização da dieta e avaliação de métodos de estimativa de consumo em caprinos suplementados na caatinga. 2006. 85f. Dissertação (Mestrado em Zootecnia) Universidade Federal da Paraíba, Centro de Ciências Agrárias, Areia-PB, 2006.

MACHADO, M. F.; GOMES, L. J.; MELLO, A. A. Caracterização do consumo de lenha pela atividade de cerâmica no Estado de Sergipe. Revista Floresta, Curitiba, v. 40, n. 3, p. 507-514, 2010.

MEDEIROS, S. S. et al. Sinopse do censo demográfico para o semiárido brasileiro. Campina Grande: INSA, 2012. 103 p.

MENDONÇA JÚNIOR, A. F. M.; BRAGA, A. P.; GALVÃO, R. J. D. Composição bromatológica, consumo e digestibilidade in vivo de dietas com diferentes níveis de feno de catingueira (Caesalpinia pyramidalis Tul), fornecidas para ovinos SRD. Revista de Biologia e Ciências da Terra, São Cristóvão, v. 8, n. 1, p. 135-142, 2008.

PRADO, D. E. As caatingas da América do Sul. In: ECOLOGIA e Conservação da Caatinga. Recife: Ed. Universitária da UFPE, 2003. 822 p.

PFISTER, J. A.; MALECHEK, J. C. Dietary selection by goats and sheep in a deciduous woodland of Northeastern, Brazil. Journal of Range Management, Arizona, v. 39, n. 1, p. 24-28, 1986.

REDE DE MANEJO FLORESTAL DA CAATINGA. Protocolo de medições de parcelas 
permanentes. Comitê Técnico Científico. Recife: Associação Plantas do Nordeste, 2005. 21 p.

RODAL, M. J. N.; SAMPAIO, E. V. S. B.; FIGUEIREDO, M. A. Manual sobre métodos de estudos florístico e fitossiciológico: ecossistema caatinga. Brasília: SB, 2013. 24 p.

SANTANA, D. F. Y. et al. Caracterização da caatinga e da dieta de novilhos fistulados, na época chuvosa, no semiárido de Pernambuco. Revista Brasileira de Zootecnia, Viçosa, MG, v. 40, n. 1, p. 69-78, 2011.

SILVA, D. J.; QUEIROZ, A. C. Análises de alimentos: métodos químicos e biológicos. 3. ed. Viçosa, MG: Editora UFV, 2002. 235 p.

SILVA, E. M. et al. Diagnóstico do uso de leguminosas em propriedades rurais no município de Aparecida-PB. Revista Verde de Agroecologia e Desenvolvimento Sustentável, Pombal, v. 7, n. 3, p. 212-217, 2012.

SILVA, L. B. et al. Anatomia e densidade básica da madeira de Caesalpinia pyramidalis Tul. (Fabaceae), espécie endêmica da caatinga do Nordeste do Brasil. Acta botânica brasílica, Belo Horizonte, v. 23, n. 2, p. 436-445, 2009.

SILVA, N. L. et al. Pastoreio de curta duração com ovinos em caatinga raleada no sertão Cearense. Pesquisa Agropecuária Brasileira, Brasília, v. 34, n. 1, p. 135-140, 1999.

SOARES, C. P. B.; OLIVEIRA, M. L. R. Equações para estimar a quantidade de carbono na parte aérea de árvores de eucalipto em Viçosa, Minas Gerais. Revista Árvore, Viçosa, MG, v. 26, n. 5, p. 533-539, 2002.

SOARES, C. P. B.; PAULA NETO, F.; SOUZA, A. L. Dendrometria e inventário florestal. 2. ed. Viçosa, MG: Editora UFV, 2011. 272 p.

SOUZA, L. V. S. et al. Qualidade nutricional de plantas forrageiras de ocorrência na caatinga. Enciclopédia Biosfera, Goiânia, v. 9, n. 16, p. 179-185, 2013.

STATSOFT. Statistica 5.0 for Windows [Computer program manual]. Tulsa: StatSoft, 1999.

UNIVERSIDADE FEDERAL DE CAMPINA GRANDE. Departamento de Ciências Atmosféricas. Precipitação mensal - estado da Paraíba. [Campina Grande, 2017]. Disponível em: http://www. dca.ufcg.edu.br/clima/chuvapb.htm. Acesso em: 18 dez. 2017.

VAN SOEST, P. J. Nutritional ecology of the ruminant. 2nd ed. Ithaca: Cornell University Press, 1994. $476 \mathrm{p}$.

ZANINE, A. M. et al. Composição bromatológica de leguminosas do semiárido brasileiro. Livestock Research for Rural Development, Cali, v. 17, n. 8, p. 01-05, 2005. 